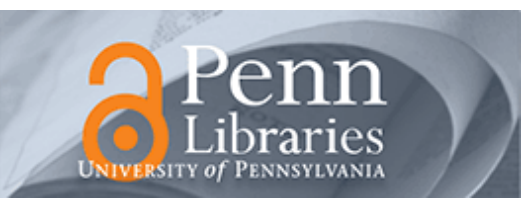

University of Pennsylvania ScholarlyCommons

January 1996

\title{
Where the Homeless Come From: A Study of the Prior Address Distribution of Families Admitted to Public Shelters in New York City and Philadelphia
}

\author{
Dennis P. Culhane \\ University of Pennsylvania, culhane@upenn.edu \\ Chang-Moo Lee \\ University of Pennsylvania \\ Susan M. Wachter \\ University of Pennsylvania, wachter@wharton.upenn.edu
}

Follow this and additional works at: https://repository.upenn.edu/spp_papers

\section{Recommended Citation}

Culhane, D. P., Lee, C., \& Wachter, S. M. (1996). Where the Homeless Come From: A Study of the Prior Address Distribution of Families Admitted to Public Shelters in New York City and Philadelphia. Retrieved from https://repository.upenn.edu/spp_papers/63

Reprinted from Housing Policy Debate, Volume 7, Issue 2, 1996, pages 327-365.

We have contacted the publisher regarding the deposit of this paper in ScholarlyCommons@Penn. No response has been received.

This paper is posted at ScholarlyCommons. https://repository.upenn.edu/spp_papers/63

For more information, please contact repository@pobox.upenn.edu. 


\title{
Where the Homeless Come From: A Study of the Prior Address Distribution of Families Admitted to Public Shelters in New York City and Philadelphia
}

\begin{abstract}
This study investigates hypotheses regarding the association of census tract variables with the risk for homelessness. We used prior address information reported by families entering emergency shelters in two large U.S. cities to characterize the nature of that distribution.

Three dense clusters of homeless origins were found in Philadelphia and three in New York City, accounting for 67 percent and 61 percent of shelter admissions and revealing that homeless families' prior addresses are more highly concentrated than the poverty distribution in both cities. The rate of shelter admission is strongly and positively related to the concentration of poor, African-American, and female-headed households with young children in a neighborhood. It is also correlated with fewer youth, elderly, and immigrants. Such areas have higher rates of unemployment and labor force nonparticipation, more housing crowding, more abandonment, higher rates of vacancy, and higher rent-to-income ratios than other areas.
\end{abstract}

\section{Keywords}

homeless, housing, neighborhood, poverty distribution, rent-to-income ratio

\section{Comments}

Reprinted from Housing Policy Debate, Volume 7, Issue 2, 1996, pages 327-365.

We have contacted the publisher regarding the deposit of this paper in ScholarlyCommons@Penn. No response has been received. 


\title{
Where the Homeless Come From: A Study of the Prior Address Distribution of Families Admitted to Public Shelters in New York City and Philadelphia
}

\author{
Dennis P. Culhane, Chang-Moo Lee, and Susan M. Wachter \\ University of Pennsylvania
}

\begin{abstract}
This study investigates hypotheses regarding the association of census tract variables with the risk for homelessness. We used prior address information reported by families entering emergency shelters in two large U.S. cities to characterize the nature of that distribution.

Three dense clusters of homeless origins were found in Philadelphia and three in New York City, accounting for 67 percent and 61 percent of shelter admissions and revealing that homeless families' prior addresses are more highly concentrated than the poverty distribution in both cities. The rate of shelter admission is strongly and positively related to the concentration of poor, African-American, and female-headed households with young children in a neighborhood. It is also correlated with fewer youth, elderly, and immigrants. Such areas have higher rates of unemployment and labor force nonparticipation, more housing crowding, more abandonment, higher rates of vacancy, and higher rent-to-income ratios than other areas.
\end{abstract}

Keywords: Homeless; Housing; Neighborhood

\section{Introduction}

Researchers and policy makers have increasingly emphasized the structural and dynamic nature of the homelessness problem (Burt 1992; Interagency Council for the Homeless 1994; Piliavin et al. 1993). Research on the structural factors associated with homelessness has used primarily intercity homelessness rates (point prevalence) as the dependent measure, attempting to identify the associated housing, population, income, and policy factors (Applebaum et al. 1991, 1992; Burt 1992; Elliot and Krivo 1991; Quigley 1991; Tucker 1987). This research has yielded significant though inconsistent results, particularly regarding many predicted housing and income variables. This article addresses the same issue, using intracity data, aggregated by census tract, based on the prior addresses of homeless families in two large U.S. cities. 


\section{Literature review}

Basic research on contemporary homelessness has employed primarily cross-sectional survey methods designed to enumerate the population and document its demographic characteristics. While providing a detailed profile of the population and many of its needs, this method has had limitations. It has produced a static representation of a dynamic problem; it has identified where and in what condition people end up as homeless, but not where they come from or go to; and while it has identified the characteristics of individuals that increase their vulnerability to the condition, the data have not been well suited to assessing the social processes that contribute to that vulnerability. To some extent, public policies and programs designed to address homelessness have shared these limitations. Most homelessness program development has focused on expanding the availability of residential and supportive services that target currently homeless persons and families. Program development has focused less on forestalling the housing emergencies of the many more individuals and families who, without intervening assistance, will move in and out of homelessness over time. Homelessness programs have also targeted individuals for intervention, and not the communities or institutions from which they come or the social and economic forces that have put these individuals at risk. However, evidence has emerged of a shift in both the research and policy sectors toward a greater understanding of the structural and dynamic nature of the homelessness problem.

In the research sector, several investigators have applied or argued for the use of geographic methods to study structural aspects of the homelessness problem (Kearns and Smith 1994; Wallace 1989, 1990; Wolch and Dear 1993). Most commonly, researchers have attempted to identify the socioeconomic factors that correspond to the spatial distribution of homelessness, using data on intercity homelessness rates as the dependent variable (Applebaum et al. 1991, 1992; Burt 1992; Elliot and Krivo 1991; Quigley 1991; Ringheim 1990; Tucker 1987). Based on this research, homelessness appears to vary by socioeconomic conditions, although specific study findings have been inconsistent. Tucker (1987), in one of the first applications of this method, argued that cities with rent control had higher homelessness rates, based on data from an early survey of city shelter capacity by the U.S. Department of Housing and Urban Development (HUD 1984). Applebaum and colleagues (1991, 1992) identified major flaws in Tucker's approach and provided counterevidence that low vacancy rates, as a proxy for tight housing markets, were more closely related to HUD's intercity 
homelessness rates. Elliot and Krivo (1991), using the same data, found that the availability of low-income housing and lower per capita expenditures on mental health care were significantly related to homelessness rates but that poverty and unemployment rates were not. In a test of several more carefully specified models of intercity homelessness rates, Burt (1992) found that per capita income, the poverty rate, and the proportion of singleperson households combined to explain more than half the variation in homelessness rates in high-growth cities, interpreted as evidence that more affluent households and a greater number of households with single people put pressure on the housing choices of poorer people.

A limitation of this research, and perhaps an explanation for study differences, is the reliability and validity of the dependent variable. While perhaps the most widely attainable proxy for the size of the homelessness problem across locales, point prevalence measures are difficult to obtain reliably from place to place. The HUD estimates (1984) used by Tucker (1987), Applebaum et al. (1991), Elliot and Krivo (1991), and Quigley (1991) were based on a key informant survey in 60 cities. HUD officials asked field staff to report on the capacity of localities' emergency shelters and the estimated number of street homeless in their areas; thus, these estimates were not based on a systematic count. The comparability of study findings based on the HUD estimates is further complicated by the various authors' use of different jurisdictional boundaries in calculating rates. The Urban Institute estimates used by Burt (1992) were derived from results of a larger, more systematic survey of shelter providers and based on a hypothetical ratio of street homeless to sheltered homeless; but again, they were not derived from an actual count.

Even if estimates were reliably obtained across jurisdictions, their validity as comparable measures of the extent of homelessness across locales would be confounded by the highly variant responses of those locales to the problem of homelessness. To a significant degree, the daily size of the sheltered population, typically the largest component of the homeless count, is supplyand policy-driven (Burt 1994; Culhane 1992). The elasticity of the supply of shelter beds defines access to the shelter system, which in turn is a function of local policies governing admission criteria, length-of-stay limits, and the flexibility of resources to meet demand. Other policies, such as copayment requirements, sobriety checks, and treatment mandates, as well as the overall quality of facilities, are also likely to influence some clients' perceptions of whether accepting accommodations in a shelter has relative appeal over other options, and for what duration. 
Likewise, opportunities for exiting homelessness will affect the duration of episodes; in general, more programs to facilitate exit from homelessness should decrease time to exit and correspondingly produce a lower daily census. ${ }^{1}$ Each of these factors is likely to exercise a systematic influence on a city's average shelter stay and shelter capacity, which in turn will play a determining role in the point prevalence of homelessness.

Recent longitudinal research has suggested the potential relevance of a structural and dynamic model of homelessness and has raised questions about the adequacy of point prevalence data for measuring the homelessness problem. Analyses of administrative data (Burt 1994; Culhane et al. 1994), a national telephone survey (Link et al. 1994), and a housing survey in New York City (Stegman 1993) have all found that as much as 3 percent of the population experienced an episode of "literal" homelessness between 1988 and 1992, suggesting a high degree of turnover in the homeless population. Longitudinal research based on tracked samples of homeless persons (Fournier et al. 1994; Koegel and Burnam 1994; Piliavin et al. 1993; Robertson, Zlotnick, and Westerfelt 1994; Wright and Devine 1995) has also documented the often transitory, intermittent nature of homelessness. Most shelter users appear to mobilize resources and community ties to avoid the shelters most of the time. Hopper $(1990,1995)$ has characterized these informal networks as the "economies of makeshift." Unfortunately, the nature of these support systems, and the factors that strain or enhance their supportive capacity, are not well understood (see related discussions in Burt [1994], Piliavin et al. [1993], and Rossi [1994]).

In the policy sector, recent proposals have discussed the dynamic and structural aspects of the homelessness problem. Most recently, the Clinton administration's plan Priority Home: The Federal Plan to Break the Cycle of Homelessness (Interagency Council for the Homeless 1994) offers a social and economic analysis of the causes of homelessness, as well as a distinction between chronic and episodic homelessness. ${ }^{2}$ Based on this analysis, the plan argues for making homelessness prevention a priority for future federal policy. The Clinton plan describes

\footnotetext{
${ }^{1}$ Paradoxically, the opposite could also occur, as may occur in some programs that require a minimum stay to become eligible for exit programs, or as may occur as a result of increased demand for emergency shelter to obtain access to exit programs.

${ }^{2}$ Kondratas (1994) observed that the Bush administration plan also emphasized homelessness prevention and the integration of homeless populations into mainstream social programs.
} 
broad legislative initiatives intended to approach that goal, such as the administration's health care and welfare-reform proposals, expansion of the earned-income tax credit, and increased homeownership and rental-assistance opportunities. ${ }^{3}$ In addition, the plan's core policy objective-that localities establish an organized "continuum of care" for the homeless service systemacknowledges the need for preventive and long-term housing stabilization efforts, as well as traditional remedial strategies, to reduce the prevalence of homelessness.

The plan does not address how localities might plan for prevention programs and offers few specifics regarding implementation other than in the broad terms of the major legislative initiatives described above. Given that many of the proposals in the federal plan are placed in the context of the scientific literature, the gap in the plan could well be a reflection of a gap in prior research. Some conceptual elaboration of homelessness prevention programming has appeared in the literature (Jahiel 1992; Lindblom 1991), but the available empirical literature is limited (U.S.

Department of Health and Human Services 1991). The literature on program targeting has been comparably sparse (Knickman and Weitzman 1989). Researchers have not provided a method for helping policy makers to determine where homelessness prevention resources should be targeted, nor have they clearly documented the factors they should focus on.

Our present study is an attempt to contribute to the continuing integration of a structural and dynamic model of homelessness in the research and policy sectors, both by beginning to answer the "where to target" question facing the planners of homelessness prevention programs and by adding to researchers' tools for investigating the structural correlates of homelessness (or the "what to target" question facing planners). This study uses the prior-address information reported by persons admitted to the Philadelphia and New York City shelter systems to construct an intracity index for the rate of homelessness by census tract and identifies census tract variables that correspond to that distribution. An intracity measure has the following methodological advantages over the intercity point prevalence measures described above: (1) in general, it is concerned not with the exactness of a count for a given day but with identifying a representative sample of persons from whom prior-address information can be obtained over a given period of time; and

\footnotetext{
${ }^{3}$ Regardless of the particular merits or shortcomings of many of these proposals, their future is uncertain in light of recent changes in the composition of the U.S. Congress.
} 
(2) it is not confounded by local policies and regulations that affect shelter supply and stay patterns because those factors would presumably have a similar impact across a city's jurisdiction, particularly in centrally administered shelter systems such as those studied here. While intercity analyses permit researchers to assess the policy and social factors that vary in relation to homelessness rates among cities, an intracity approach allows them to characterize spatial variations within a city. Thus, an intracity approach may contribute to an understanding of the "makeshift economies" that beget homelessness and of the processes that contribute to the success or failure of the makeshift economies in mediating housing instability.

\section{Social selection processes of homelessness}

To develop a theory for generating hypotheses, our study builds on previous theoretical work (Blau 1992; Burt 1992; Culhane 1990; Hopper and Hamberg 1986; Jahiel 1992; Rossi 1989; among others). Briefly, the model argues that homelessness is a consequence of a combination of housing, income, population, and policy factors that have significantly increased the probability that poor persons will live in precarious housing arrangements. Among the precariously housed, a shelter admission is most likely to occur following some household crisis (e.g., job loss, marital separation, benefit termination, utility disconnection, hospitalization, incarceration, family conflict) and most frequently occurs among persons who have the least amount of familial, social, or public support. These people include unemployed single mothers who are caring for young children and do not receive child support payments; adults with disabilities, including people with mental disorders and people addicted to drugs or alcohol; the undereducated and underemployed, particularly those ineligible for unemployment insurance or general assistance welfare programs; and people with weak familial supports, such as those fleeing abusive families and individuals who were reared in foster care or otherwise unsupportive family environments. The precariously housed are expected to be concentrated in certain areas, because of both selective migration and restrictions on their housing choice.

A family crisis or household disruption does not necessarily lead to shelter use, but such a result is more likely in the context of shortages of affordable and suitable housing for people with very low incomes. The risk of homelessness would likely be greater if the disruption were preceded by residence in poor-quality housing or if it resulted in a subsequent move to such housing. 
Thus, one would expect to find that public-shelter admissions are most often generated in the lowest rent neighborhoods where poor people exhaust the opportunities most accessible to them. Such areas are more likely to have generally distressed housing conditions, as indicated by more vacancies and abandonment. Moreover, despite having the lowest-cost housing available, such areas may nevertheless be "unaffordable" to the people who live in them, leading some to live in crowded or doubled-up arrangements (in subfamilies).

The relevance of the other major component to the housing affordability problem-low income-is likely to be evident by the higher rates of poverty and joblessness in such neighborhoods. Problems with access to the labor market are indicated by higher rates of unemployment, less full-time employment, and less participation in the labor force. Public assistance presumably reduces the risk of homelessness in an area (compared with poor areas where people receive less public assistance), but it also may be associated with an increased risk of homelessness to the extent that receipt of public assistance indicates very low income and less participation in the labor market.

It is presumed that the housing and income problems described above have differentially affected African Americans because of historical patterns of migration, economic development, residential segregation, and discrimination. Other ethnic minorities, such as Hispanics and immigrant groups, may also face increased risk of homelessness due to poverty, restricted labor market access, and segregation in poorer-quality housing.

\section{Hypotheses and research questions}

First, our study explores the spatial distribution of the residential origins of homeless families through spatial statistics and thematic maps, permitting us to compare the degree of clustering and segregation in those distributions between cities and among boroughs within New York City. The descriptive analyses also identify the degree to which the homeless and poverty distributions differ in their concentration, unevenness, and clustering, to further qualify the nature of the prior-address distribution of homeless families.

To understand the marginal effect of various factors on the spatial distribution of homeless families' prior addresses, we used cross-sectional data from the 1990 decennial census (measuring demographic composition, economic status, and 
housing and neighborhood factors) in a regression analysis to test some of the assumptions of the theoretical model regarding an area's potential risk. We hypothesize that the variables defined in table 1 will be significantly associated with the rate of family shelter admission by census tract.

\section{Table 1. Variable Definitions and Hypotheses}

\begin{tabular}{|c|c|c|}
\hline Variable & Definition & ted Sign \\
\hline \multicolumn{3}{|l|}{ Demographic } \\
\hline RBLACK & Ratio of black persons & + \\
\hline RSPAN & Ratio of Hispanic persons & + \\
\hline RUNDER18 & Ratio of persons under 18 & + \\
\hline ROVER64 & Ratio of persons over 64 & + \\
\hline RNOHIGH & Ratio of persons without high school diploma & + \\
\hline RFHHOLD & Ratio of female-headed households & + \\
\hline RFYOUCHD & Ratio of female-headed households with & \\
\hline ROLDFAM & $\begin{array}{l}\text { children under six years old } \\
\text { Ratio of families with householder over } 64 \\
\text { years old }\end{array}$ & + \\
\hline RSUBFAM & Ratio of subfamilies & + \\
\hline RGRPQUAT & $\begin{array}{l}\text { Ratio of noninstitutionalized persons in } \\
\text { group quarters }\end{array}$ & + \\
\hline RFRBRN70 & $\begin{array}{l}\text { Ratio of the foreign-born who immigrated } \\
\text { after } 1970\end{array}$ & + \\
\hline \multicolumn{3}{|l|}{ Economic } \\
\hline RUNEMP & Ratio of unemployment & + \\
\hline MNHHPAI & Mean household public assistance income & + \\
\hline MEDHHINC & Median household income & - \\
\hline RNOPOV & Ratio of persons below poverty level & + \\
\hline RNOWORK & Ratio of persons not in labor force & + \\
\hline RTMPWORK & $\begin{array}{l}\text { Ratio of persons working under } 18 \text { hours } \\
\text { per week }\end{array}$ & + \\
\hline \multicolumn{3}{|c|}{ Housing and neighborhood quality } \\
\hline MEDVALUE & Median property value & - \\
\hline MEDCOREN & Median contract rent & - \\
\hline RRENT & Ratio of rental units & + \\
\hline RENTHINC & $\begin{array}{l}\text { Ratio of median contract rent to median } \\
\text { household income }\end{array}$ & + \\
\hline RCROWD & $\begin{array}{l}\text { Ratio of housing units with more than two } \\
\text { persons per room }\end{array}$ & + \\
\hline RVAC & Ratio of vacant units & + \\
\hline RBOARDUP & Ratio of boarded-up housing units & + \\
\hline
\end{tabular}

Note: Dependent variable is log(ratio of homelessness occurrence +1$)$. All ratios are in percent.

We expected variations by city to affect our results, given known differences in several housing market factors such as population loss, a much higher proportion of single-family housing, and overall lower housing costs in Philadelphia. We also explored 
differences between low- and higher-income areas to test for factors that may differentially expose persons to homelessness in areas disaggregated by median income.

\section{Procedures}

\section{Database development}

Data sources. New York City and Philadelphia systematically register all users of public shelters through automated client management information systems (see Culhane et al. 1994). As part of the shelter admission process, families in New York City and all households in Philadelphia are asked to report their "last address." This question may be variously interpreted by families requesting shelter. For purposes of the present study, we assume the addresses, through their aggregation, to be a proxy for the areas in which families entering the shelter have had some recent residence. For consistency between sites, only data on families were included in the study. To create an admission record in Philadelphia, clients must present two forms of identification that together must include a social security number and a Philadelphia street address. ${ }^{4}$ The Philadelphia database begins December 21, 1989, and is current to April 1, 1994. It includes records for 9,160 families. In New York City, shelter admission information for families may be verified against a family's information in the New York State Welfare Management System at the time of admission, if the family is registered in that system. The data from New York used for this study begin April 1, 1987, and are current to April 1, 1994. They include records for 71,035 households.

Geocoding procedures. To construct a database of addresses aggregated by census tract, we overlaid the addresses from the Philadelphia data set with the census tract coverage from the TIGER/Line file (U.S. Department of Commerce 1993). We

\footnotetext{
${ }^{4}$ Some persons may be admitted to a shelter with a non-Philadelphia street address because they can otherwise prove that they have been in Philadelphia for a minimum of six weeks (thereby meeting the residency requirement), because they are sheltered as part of the mandatory shelter provision policy in effect on extremely cold or hot days, or because they have been admitted in violation of policy. Some persons do not report a prior address because they enter the shelter system after-hours (after 5 p.m.), thereby avoiding the complete intake interview. Families are permitted to avoid the intake interview if they stay for only one night; they are required to complete the intake interview if they stay for consecutive nights.
} 
processed the address data from New York City through Geosupport, a program for normalizing street addresses and for producing geocodes for census blocks and tracts maintained by the New York City Department of City Planning.

For both cities, we first matched client address data to the respective base map files (see table 2). For New York City, 70 percent of the cases had an address that matched the Department of City Planning's geographic files. Shelter addresses were removed to produce the study population. The unmatched cases constitute 30 percent of the total and include rejected in-city addresses, in-state non-New York City addresses, out-of-state addresses, and missing addresses. In Philadelphia, 59 percent of the cases had an address that matched the TIGER file. Again, shelter addresses were removed to produce the study population. The unmatched cases (41 percent) include rejected in-city addresses, in-state non-Philadelphia addresses, and out-of-state addresses, but are composed largely of missing addresses. We conducted further analyses to determine the representativeness of the study population, including comparing the race and ethnicity of matched versus unmatched cases, comparing the geographic distribution of in-city addresses (both those that did and those that did not match the respective base maps by zip code), and comparing the prior addresses of households with single and multiple admissions to shelter (see appendix for a more complete discussion).

Table 2. Qualification of Study Populations

\begin{tabular}{lrr} 
& New York & Philadelphia \\
\hline Address-matched sample & 49,604 & 5,375 \\
Shelter addresses & 481 & 319 \\
Family & 49,123 & 5,056 \\
Nonmatched sample & 21,431 & 3,785 \\
In-city $^{\mathrm{a}}$ & 9,990 & 858 \\
In-state (not in city) $^{\mathrm{b}}$ & 429 & 24 \\
Out-of-state $^{\mathrm{c}}$ & 2,120 & 42 \\
Missing $^{\mathrm{d}}$ & 8,892 & 2,861 \\
Total households & 71,035 & 9,160 \\
\hline
\end{tabular}

${ }^{a}$ In-city rejected addresses represent 16.8 percent of the total in-city addresses reported in New York City. The rejected addresses correlate with the matched addresses by zip code at $r=0.877$. For Philadelphia, the rejected addresses represent 13.8 percent of the in-city addresses and correlate at $r=0.972$ with the matched addresses by zip code.

${ }^{b}$ In New York, the most frequent counties of origin outside New York City are

Westchester (48 cases), Suffolk (46 cases), and Ulster (20 cases).

${ }^{c}$ Outside of New York, the most frequent states/territories of origin are Puerto Rico (422 cases), New Jersey (244 cases), Pennsylvania (137 cases), California (117 cases),

South Carolina (93 cases), North Carolina (90 cases), Connecticut (83 cases), and Massachusetts (81 cases).

d 12.5 percent missing in New York City, and 31.2 percent missing in Philadelphia. 


\section{Descriptive measures of area variations in homelessness rates}

Concentration by census tract. To analyze the two-dimensional concentration of the prior addresses of homeless households with thematic maps by census tract, we used the location quotient (LQ). The LQ is frequently used to identify the proportionate distribution of a given object group among areas (Bendavid-Val 1983). The LQ refers to the ratio of the fractional share of the subject of interest at the local level to the same ratio at the regional level (see appendix). This article uses the census tract as the equivalent of the local unit and the city or borough as the equivalent of the regional unit. ${ }^{5}$

Although the LQ is used to examine the two-dimensional aspects of a spatial distribution, other indices are required to quantify the relational aspects of that spatial distribution within and among jurisdictions. For this study, we selected three additional indices to measure these relational aspects: unevenness, contiguity, and clustering.

Unevenness. Unevenness refers to how unequally an object or social group is distributed among defined areas in a given jurisdiction. For example, a minority group is said to be "segregated" if it is unevenly distributed over census tracts in segregation studies (Massey and Denton 1988; White 1983). The most widely used measure of unevenness is the index of dissimilarity. It measures departure from evenness by taking the absolute deviation of the population-weighted mean of every census tract's object-group proportion from the city's object-group proportion and expressing that quantity as a proportion of its theoretical maximum (James and Taeuber 1985) (see appendix).

Contiguity. A second distributional attribute is the degree of spatial contiguity. While unevenness deals with the distribution of an object group within a set of areal units overall, contiguity is concerned with the similarity in concentration between adjoining areal units. In this study, we used an index of spatial autocorrelation, Moran's I (Odland 1988), to measure the degree of contiguity (see appendix).

Clustering. The third dimension to the spatial distribution of an object group is clustering. The contiguity index captures some

\footnotetext{
${ }^{5}$ Census tracts with populations under 100 were omitted from both the descriptive and the regression analyses to avoid the outlier effects produced by small denominators.
} 
aspects of clustering because it identifies the extent to which adjoining areas have similar concentrations of a given phenomenon. However, when the object group forms highly segregated enclaves in space, the contiguity index would fail to distinguish that type of clustering. Unfortunately, a proper measure of clustering for lattice data is not available in the literature. Therefore, we developed a clustering index based on our own definition of clustering, referring to the close spatial association of areas with a high concentration of that object group (see appendix).

\section{Regression analyses}

As stated in the conceptual model, we assume the number of the prior addresses of the shelter users in each census tract to be a function of demographic composition, economic factors, and housing and neighborhood characteristics in the census tract. The mathematical form of the model can be denoted as follows:

$\log \left(H R_{i}\right)=a+b\left(X_{1 i}\right)+c\left(X_{2 i}\right)+d\left(X_{3 i}\right)+\epsilon_{i}$,

where $H R_{i}$ is the rate of shelter admission with the number of households in tract $i ; X_{1 i}$ is the set of demographic variables in tract $i ; X_{2 i}$ is the set of economic variables in tract $i ; X_{3 i}$ is the set of housing and neighborhood variables in tract $i$; $a$ is intercept; $b, c$, and $d$ are sets of the coefficients corresponding to the sets of the explanatory variables, $X_{1}, X_{2}$, and $X_{3}$, respectively; and $\epsilon_{i}$ is the error disturbance in tract $i$. Sample statistics for the variables are shown in table $3 .^{6}$

The ordinary least square (OLS) estimation is based on the assumption of constant error variance. However, data based on census tract contain sources of unequal error variance. Every census tract does not have the same physical size or equal population. Therefore, the shelter-admission rate in less-populated census tracts tends to fluctuate more than the rate in morepopulated census tracts. This situation can worsen when sheltered households are concentrated in smaller census tracts.

\footnotetext{
${ }^{6}$ In terms of explanatory variables, median property value (MEDVALUE) is missing in 99 census tracts in New York. The census tracts are mostly lowincome neighborhoods that are our main areas of interest (the mean of MEDHHINC in the 99 tracts is $\$ 20,090$, while the mean of all the tracts is $\$ 31,532)$. MEDVALUE is presumably missing in these tracts because it measures owner-occupied property values, and these areas may have too few owner-occupied properties. We dropped MEDVALUE in the final model specification, since MEDVALUE was not statistically significant in the exploratory model specifications and the loss of the observations is so large that it may produce a biased result.
} 
Table 3. Sample Statistics

\begin{tabular}{|c|c|c|c|c|c|c|}
\hline \multirow[b]{2}{*}{ Variable } & \multicolumn{3}{|c|}{ New York } & \multicolumn{3}{|c|}{ Philadelphia } \\
\hline & $N$ & Mean & Corr.* & $N$ & Mean & Corr.* \\
\hline \multicolumn{7}{|l|}{ Demographic } \\
\hline RBLACK & 2,107 & 28.675 & 0.67 & 342 & 39.712 & 0.71 \\
\hline RSPAN & 2,107 & 21.985 & 0.46 & 342 & 4.990 & 0.06 \\
\hline RUNDER18 & 2,107 & 21.823 & 0.64 & 342 & 22.027 & 0.46 \\
\hline ROVER64 & 2,107 & 13.427 & -0.50 & 342 & 15.523 & -0.24 \\
\hline RNOHIGH & 2,107 & 21.433 & 0.46 & 342 & 22.225 & 0.36 \\
\hline RFHHOLD & 2,107 & 19.325 & 0.82 & 342 & 31.992 & 0.79 \\
\hline RFYOUCHD & 2,107 & 5.352 & 0.76 & 342 & 9.167 & 0.64 \\
\hline ROLDFAM & 2,107 & 10.451 & -0.44 & 342 & 18.676 & -0.24 \\
\hline RSUBFAM & 2,107 & 5.193 & 0.58 & 342 & 8.562 & 0.69 \\
\hline RGRPQUAT & 2,107 & 1.000 & 0.09 & 342 & 2.507 & -0.04 \\
\hline RFRBRN70 & 2,107 & 18.912 & -0.05 & 342 & 3.810 & -0.22 \\
\hline \multicolumn{7}{|l|}{ Economic } \\
\hline RUNEMP & 2,107 & 9.632 & 0.63 & 342 & 11.079 & 0.67 \\
\hline MNHHPAI & 2,107 & 1,986 & -0.52 & 342 & 3,897 & -0.21 \\
\hline MEDHHINC & 2,107 & 31,532 & -0.58 & 342 & 25,783 & -0.51 \\
\hline RNOPOV & 2,107 & 19.268 & 0.75 & 342 & 20.028 & 0.68 \\
\hline RNOWORK & 2,107 & 2.321 & 0.47 & 342 & 2.383 & 0.54 \\
\hline RTMPWORK & 2,107 & 1.773 & -0.11 & 342 & 2.101 & -0.08 \\
\hline \multicolumn{7}{|c|}{ Housing and neighborhood quality } \\
\hline MEDVALUE & 2,008 & 203,004 & -0.48 & 337 & 65,580 & -0.45 \\
\hline MEDCOREN & 2,107 & 489.000 & -0.57 & 341 & 364.173 & -0.56 \\
\hline RRENT & 2,107 & 65.143 & 0.42 & 342 & 39.669 & 0.24 \\
\hline RENTHINC & 2,107 & 1.720 & 0.54 & 341 & 1.542 & 0.15 \\
\hline RCROWD & 2,107 & 1.657 & 0.34 & 342 & 0.383 & 0.31 \\
\hline RVAC & 2,107 & 5.367 & 0.12 & 342 & 10.875 & 0.54 \\
\hline RBOARDUP & 2,107 & 0.336 & 0.36 & 342 & 2.378 & 0.72 \\
\hline RNOHMLS & 2,107 & 1.530 & NA & 342 & 1.239 & NA \\
\hline LRNOHMLS** & 2,107 & 1.812 & 1.00 & 342 & 0.495 & 1.00 \\
\hline
\end{tabular}

Note: $\mathrm{NA}=$ not applicable.

* Correlation coefficient with the dependent variable (LRNOHMLS).

** LRNOHMLS is calculated as $\log (\mathrm{RNOHMLS}+1)$ to avoid missing values.

To test the existence of heteroskedasticity, we assumed the error variance to be a decreasing function (negative exponential) of the number of households in each census tract. Technically, the log of squared residuals from the OLS estimation is regressed with the number of households. The White test for the pooled OLS estimations reveals the existence of heteroskedasticity (New York: $\chi^{2}=35.6, p$ value $=0.00 ;$ Philadelphia: $\chi^{2}=2.66$, $p$ value $=0.10$ ). To overcome heteroskedasticity, we used the square root of the estimated error variance for the weight for the final weighted least square (WLS) estimations. 


\section{Results}

\section{Descriptive measures}

In both cities in the aggregate, the distribution of homeless origins is more highly concentrated than the poverty distribution. Both cities have a lower proportion of census tracts with an LQ greater than or equal to 1.01 for homelessness than for poverty, but a higher proportion of tracts with an LQ greater than 2.00 for homelessness than for poverty (see tables 4, 5, and 6 and figures 1,2,3, and 4). Thus, while the poverty distributions are characterized by areas that are more broadly distributed but have moderately high concentration ( $\mathrm{LQ} \geq 1.01$ ), the homeless distributions are characterized by areas that are less broadly distributed but have higher concentration ( $\mathrm{QQ}>2.00$ ). Accordingly, poverty is a modest proxy for homelessness. The correlation coefficient between the two distributions (by LQ by census tract) is 0.558 in New York City and 0.640 in Philadelphia, as the relative shares of poverty are more widely distributed than the relative shares of homeless origins.

Within each city, the concentrations of homeless origins yield visually evident clusters as well, as shown in figures 1 and 3 . Nearly two-thirds (61 percent) of all homeless families from New York City from 1987 to 1994 were from the three major clusters: Harlem (15 percent of total), South Bronx (25 percent), and the Bedford-Stuyvesant-East New York neighborhoods (21 percent). Philadelphia also has three major clusters accounting for 67 percent of the homeless families' prior addresses: North Philadelphia (primarily west of Broad Street) (38 percent), West Philadelphia (20 percent), and South Philadelphia (primarily west of Broad Street) (9 percent).

The calculated indices of unevenness, contiguity, and clustering are given in table 7. For unevenness, Staten Island scores the highest, and the Bronx scores the lowest among the five boroughs in New York. The homeless families' addresses are highly segregated in Staten Island, whereas in the Bronx, where a broad set of areas is affected, homeless origins are not highly segregated. With the exception of the Bronx, each of the boroughs has much higher unevenness, or more segregation, in the distribution of the homeless than of the poor. In New York overall, the unevenness index is 35 percent higher for the homeless distribution than for the poverty distribution, and in Philadelphia, the index is 57 percent higher for the distribution of homelessness than for poverty. 

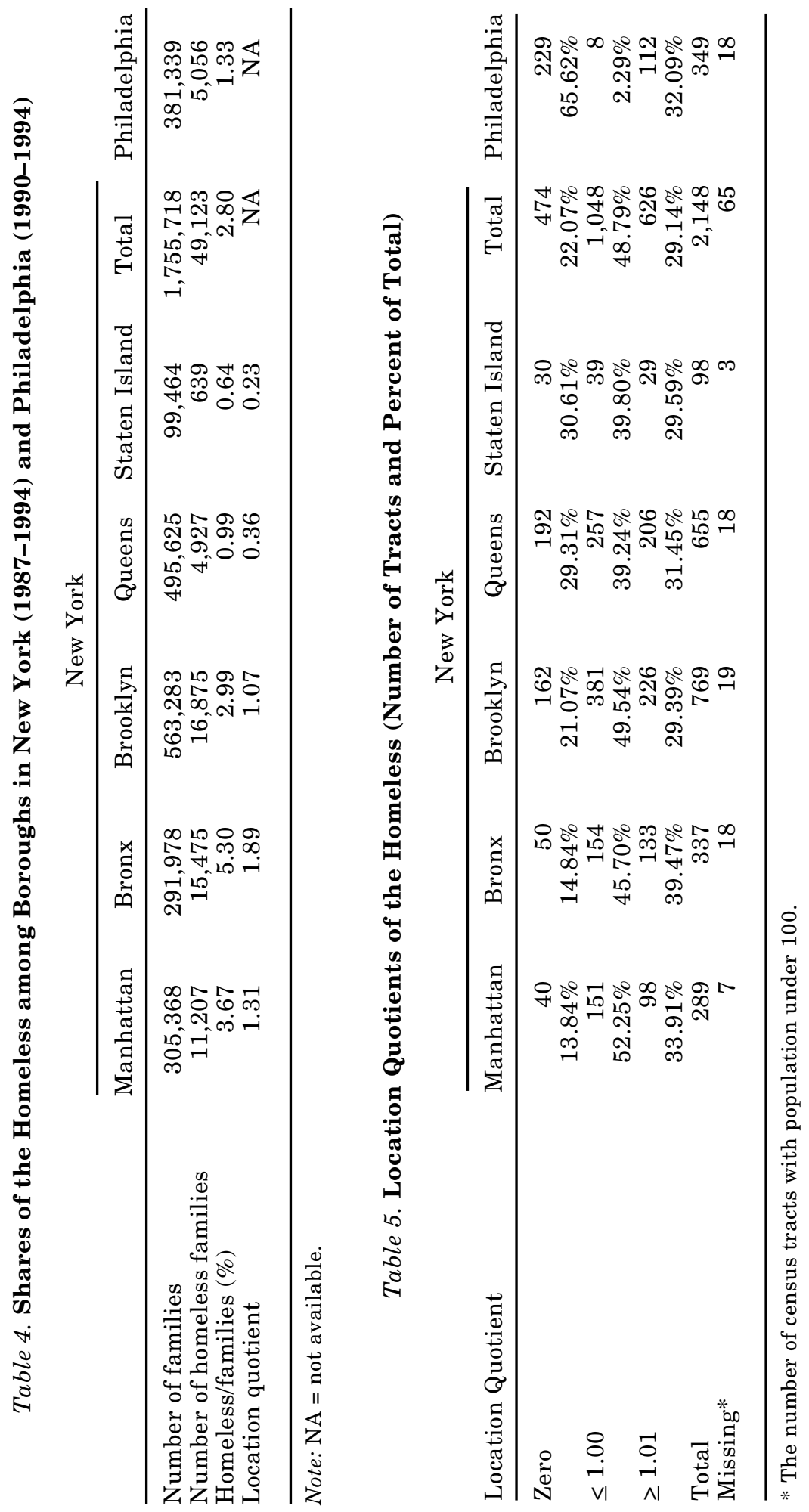

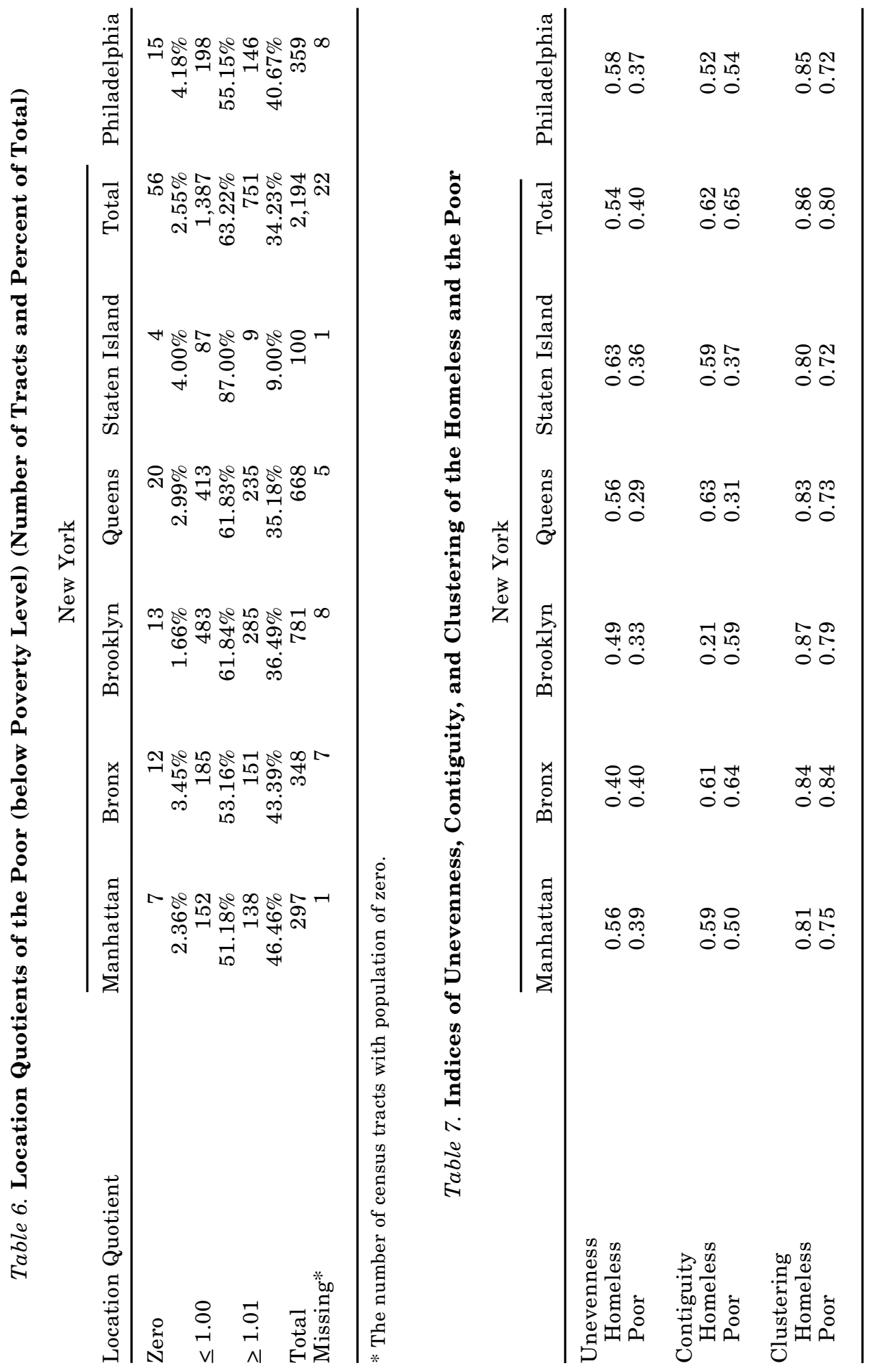
Figure 1. Census Tract Map of the Distribution of the Prior Addresses of the Homeless in Philadelphia, 1990-1994

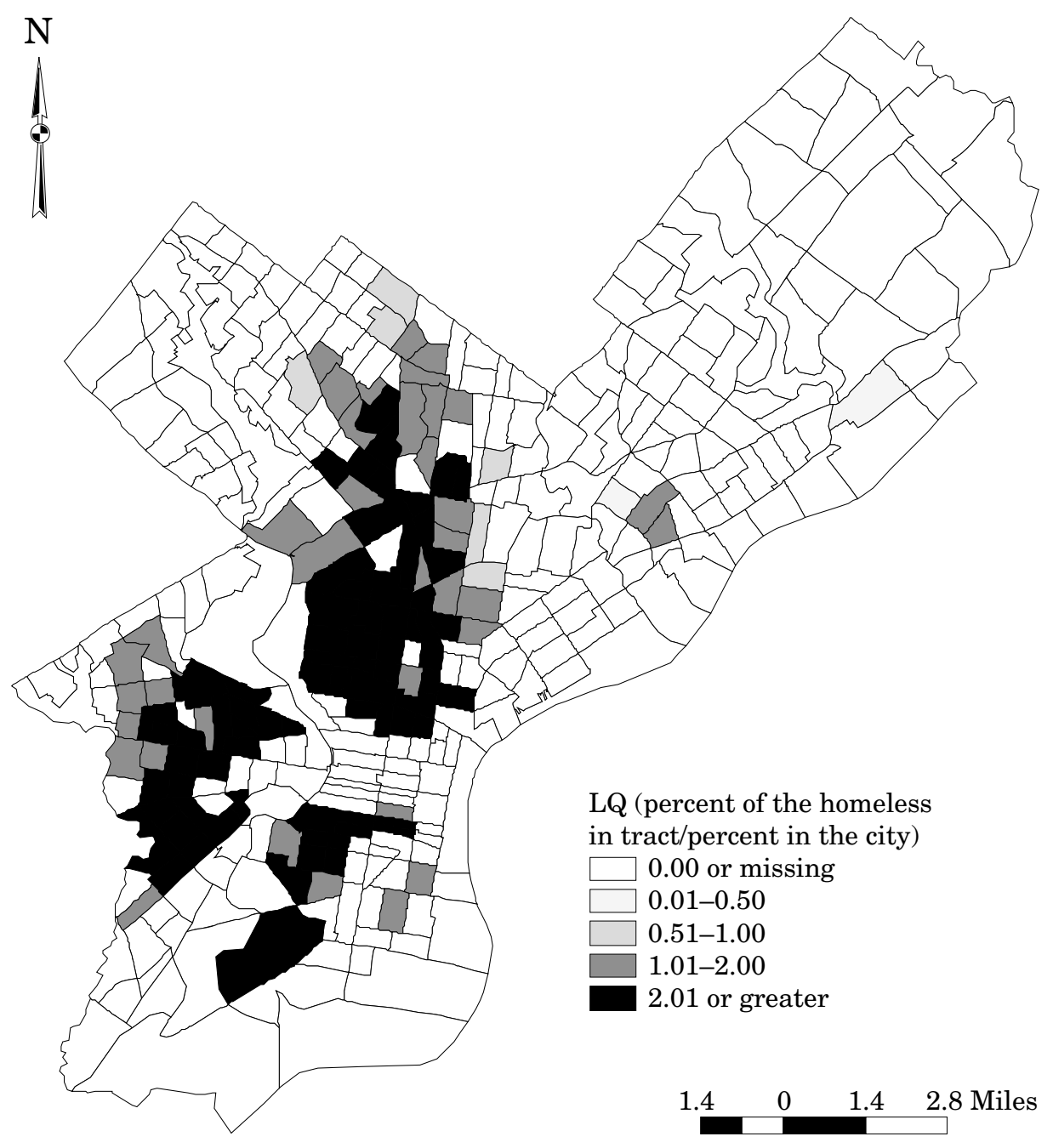

According to the clustering index created for this study, in four of the boroughs (Manhattan, Brooklyn, Queens, and Staten Island) and in both cities overall, origins of the homeless are, again, more clustered than those of the poor. The Bronx is the only jurisdiction with an equal clustering score for poverty and homelessness, again consistent with the other evidence showing a more widespread area of risk of homelessness that more closely parallels the poverty distribution. 
Figure 2. Census Tract Map of the Distribution of the Poor in Philadelphia, 1990

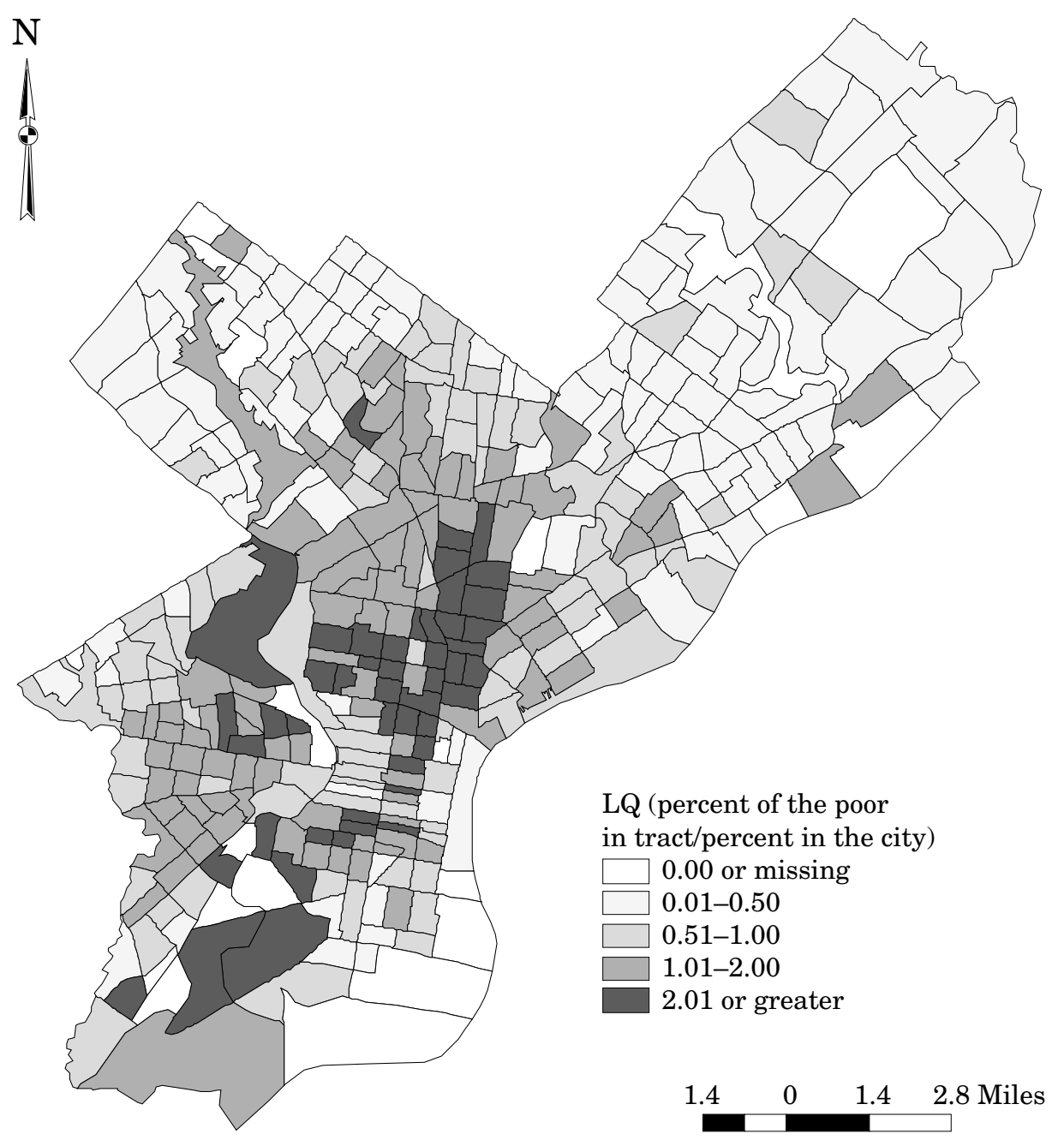

\section{Regression results}

New York, pooled sample. Among the demographic variables, indeed among all variables in the model, the proportion of African-American persons in a tract is the most important predictor, in terms of the standardized coefficient (table 8). The ratio of female-headed households with children under age six is the second strongest predictor among demographic variables, even though a variable for the ratio of female-headed households is included and is nearly significant in the predicted direction $(\beta=0.040, p=0.110)$. Contrary to our hypothesis, tracts with 
Figure 3. Census Tract Map of the Distribution of the Prior Addresses of the Homeless in New York City Boroughs, 1987-1994

LQ (percent of the homeless in tract/percent in the city)
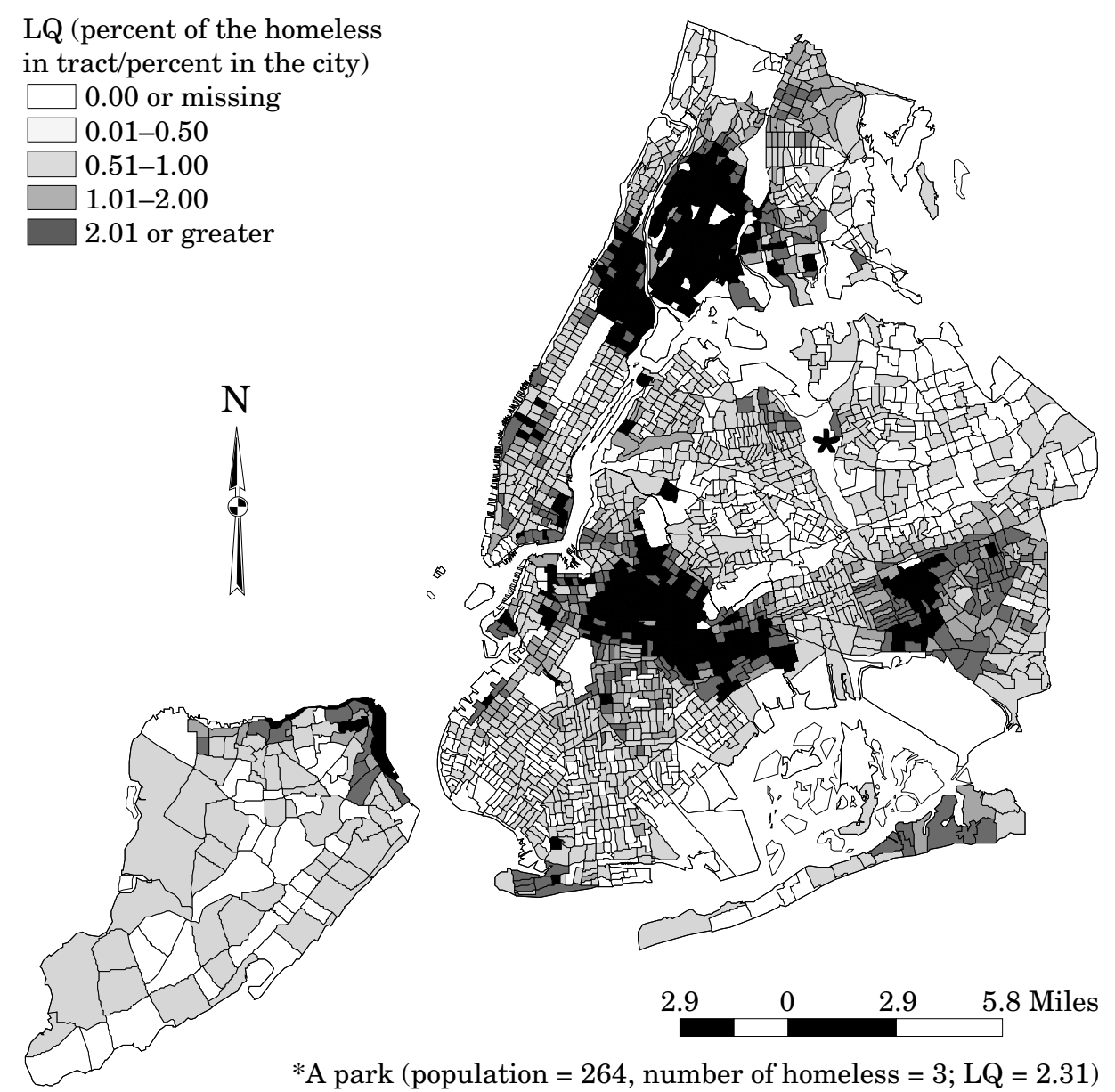

$*$ A park $($ population $=264$, number of homeless $=3 ; \mathrm{LQ}=2.31)$

more immigrant households are less likely to have shelter admissions. When this variable is removed in New York Model II, the sign for crowding reverses to become negative, suggesting that there is a positive relationship between immigrant communities and crowding that reduces the likelihood of shelter admissions. Coefficients for other demographic variables-such as the ratio of persons without a high school diploma, the ratio of subfamilies (families with children who are part of a larger household), and the ratio of Hispanic households-are significant and in the predicted positive direction, though of relatively lower magnitude. The ratio of persons under 18 was negatively associated with shelter admissions (opposite the predicted direction), as was the ratio of persons over the age of 64 . The coefficient for 
Figure 4. Census Tract Map of the Distribution of the Poor in New York City Boroughs, 1990

LQ (percent of the poor in tract/percent in the city)

0.00 or missing

$0.01-0.50$

$0.51-1.00$

$1.01-2.00$

2.01 or greater
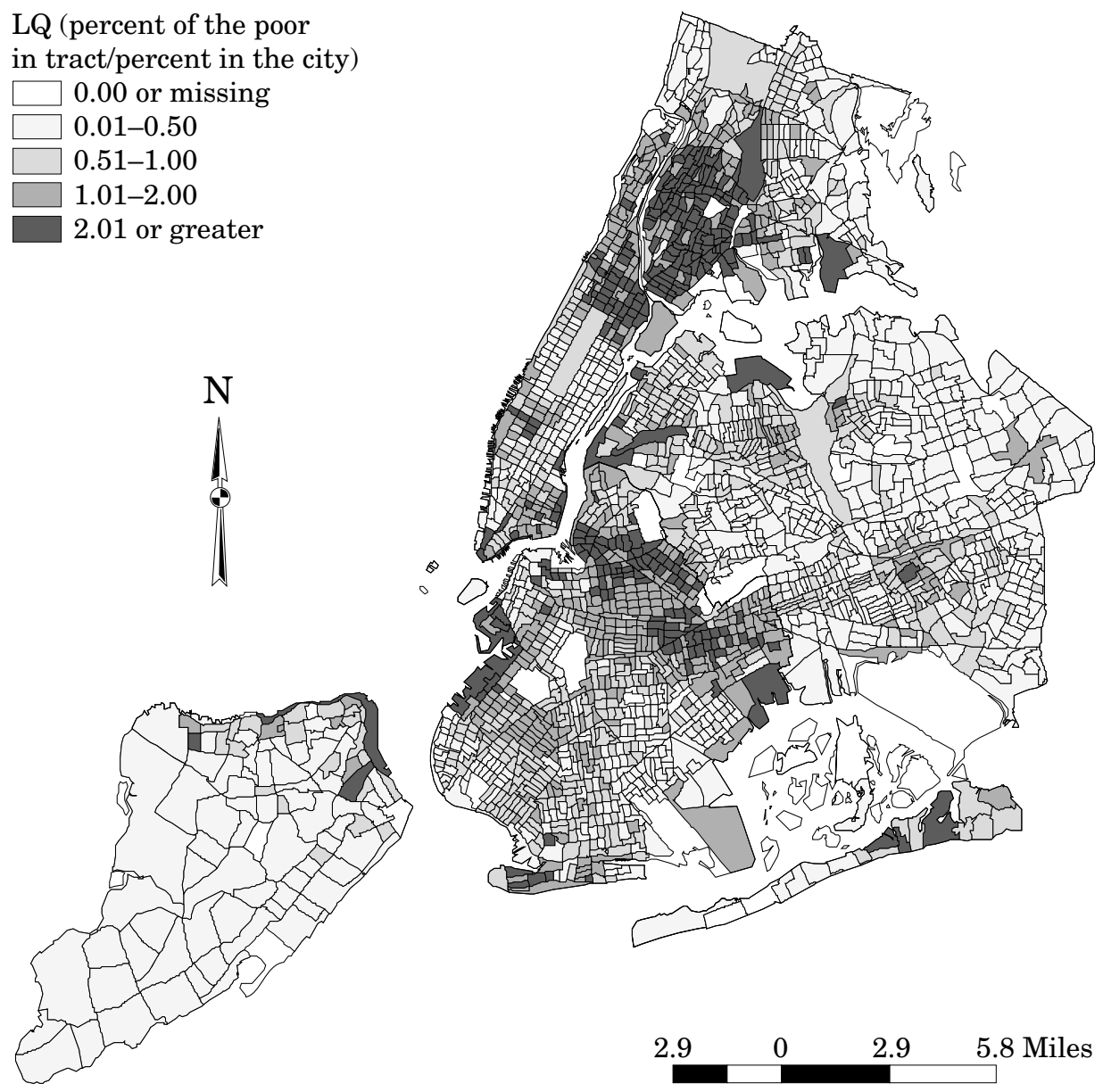

the variable for older families with children is in the predicted direction, and the coefficient for the variable for persons in group quarters is opposite the predicted direction, but neither is statistically significant.

Among economic variables, the ratio of poor households is the most important factor. The coefficient for the rate of labor force nonparticipation is also significant and in the predicted direction. The effect of the ratio of temporarily employed persons is not significant but is in the predicted direction. Effects of the ratio of unemployed persons and the mean household public assistance income variables are not significant, although the public assistance variable is nearly significant in the positive 


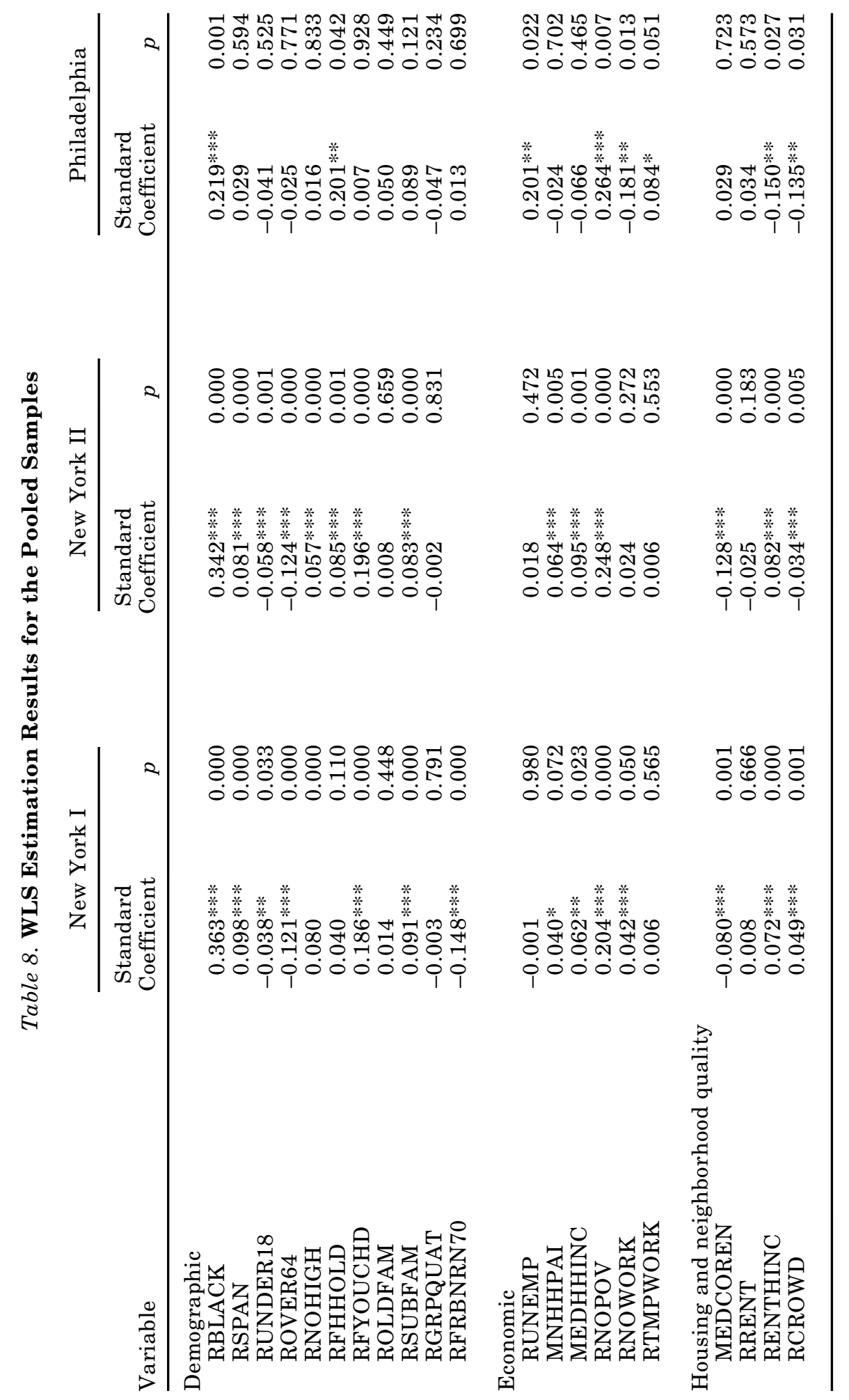



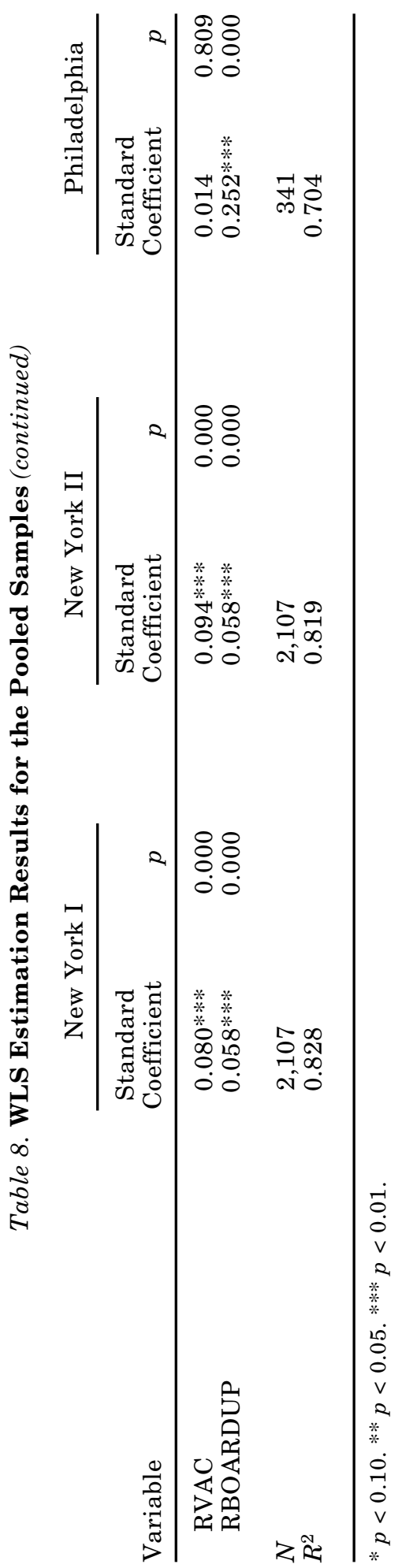
direction. The effect of median household income, which is opposite the predicted direction and statistically significant, may proxy for housing market tightness.

Among the housing and neighborhood quality factors, the rentto-income ratio is significant and positively associated with the rate of shelter admission. The association of median contract rent is negative and significant, as expected. The effect of the ratio of rental units in an area is not significant. All of the other neighborhood quality variables are significant and positively associated with the rate of shelter admission, including the vacancy rate, the ratio of boarded-up buildings, and the ratio of housing crowding.

Philadelphia. In general, the Philadelphia regression results produced findings qualitatively similar to those of New York, though fewer variables achieved a level of statistical significance. Once again, the proportion of African-American persons produced the most significant positive coefficient among demographic variables and, in Philadelphia, is the second most important predictor as measured by the standardized coefficient. The effect of the ratio of female-headed households is also significant and positive. Coefficients for the other variables are in the same direction as in New York (with the exception of percent foreign born) but do not reach statistical significance.

Among the economic factors, again, the ratio of poor persons is an important predictor (and the largest standardized coefficient in the Philadelphia model). Median household income is negatively associated but not significant. The impacts of the unemployment rate and the proportion of temporary workers are also significant (nearly significant in the case of temporary workers, $p=0.051$ ) and positively correspond to the rate of shelter admission, although neither was significant in New York. The coefficient for mean public assistance income is not significant. The coefficient for persons not in the labor force is negative, opposite that found in New York.

Among the housing and neighborhood variables (including median contract rent as a control variable), the most significant predictor (and among the most important variables in the Philadelphia model overall) is the proportion of boarded-up buildings. Coefficients for both the crowding and the rent-to-income ratio variables are significant, but with negative signs (opposite that found for New York), suggesting that homeless families in Philadelphia come from areas that are less crowded and more "affordable" than other parts of the city, perhaps because of the low 
neighborhood quality and the comparatively lower cost of housing in Philadelphia. Coefficients for the vacancy rate and proportion of rental units variables are not significant.

New York, comparison between low-income areas and higherincome areas. We used median household income to define lowand higher-income areas in New York, with the citywide median value of each tract's median household income as the break point. In New York, census tracts that have a median household income lower than $\$ 30,609$ are categorized as low-income neighborhoods and the remainder as higher-income. ${ }^{7}$

Results for most demographic variables are similar to those of the pooled sample (table 9). Coefficients relating to the proportion of African-American persons, Hispanics, female-headed households with young children, subfamilies, immigrants, and persons lacking a high school education are all significant and have the same sign in both areas as in the pooled sample.

Among economic factors, effects of the poverty rate and the rate of labor force nonparticipation are also positive and significant in both areas. However, the mean household public assistance income is now significant and positive in predicting shelter admissions in high-income areas, but negative (though not significant) in low-income areas. Unemployment and temporary work remain not significant.

Among the housing and neighborhood variables, the impact of the proportion of rental units is now significant in both areas, though positively associated in high-income tracts and negatively associated in low-income tracts. The positive association of homelessness to an area's rent-to-income ratio holds only in lowincome tracts. The neighborhood quality variables (crowding, vacancy, boarded-up buildings) are all positively associated and significant.

\section{Discussion}

While homeless households appear to come from areas with high rates of poverty, areas with the greatest risk of homelessness are generally more densely clustered than poor areas. In both cities,

\footnotetext{
${ }^{7}$ We did not make a similar comparison for Philadelphia because there were too few observations. We used the Chow test to check for structural differences with the null hypothesis that the regressions of the low- and high-income groups are identical. The results show that there are structural differences at a statistically significant level $\left(F_{22,2107}=6.12, p=0.00\right)$.
} 
Table 9. WLS Estimation Results for Low- and Higher-Income Areas in New York

\begin{tabular}{|c|c|c|c|c|}
\hline \multirow[b]{2}{*}{ Variable } & \multicolumn{2}{|c|}{ Higher-Income Tracts } & \multicolumn{2}{|c|}{ Low-Income Tracts } \\
\hline & $\begin{array}{c}\text { Standard } \\
\text { Coefficient }\end{array}$ & $p$ & $\begin{array}{c}\text { Standard } \\
\text { Coefficient }\end{array}$ & $p$ \\
\hline \multicolumn{5}{|l|}{ Demographic } \\
\hline RBLACK & $0.567 * * *$ & 0.000 & $0.362 * * *$ & 0.000 \\
\hline RSPAN & $0.150 * * *$ & 0.000 & $0.096 * * *$ & 0.000 \\
\hline RUNDER18 & -0.015 & 0.553 & -0.038 & 0.158 \\
\hline ROVER64 & $-0.173 * * *$ & 0.000 & $-0.104 * * *$ & 0.001 \\
\hline RNOHIGH & $0.068 * * *$ & 0.007 & $0.075^{* * *}$ & 0.000 \\
\hline RFHHOLD & -0.015 & 0.663 & 0.037 & 0.325 \\
\hline RFYOUCHD & $0.079 * * *$ & 0.001 & $0.187 * * *$ & 0.000 \\
\hline ROLDFAM & -0.019 & 0.570 & 0.031 & 0.213 \\
\hline RSUBFAM & $0.226 * * *$ & 0.000 & $0.082 * * *$ & 0.000 \\
\hline RGRPQUAT & $-0.050 * *$ & 0.026 & $0.030 *$ & 0.053 \\
\hline RFRBRN70 & $-0.203 * * *$ & 0.000 & $-0.130 * * *$ & 0.000 \\
\hline \multicolumn{5}{|l|}{ Economic } \\
\hline RUNEMP & -0.058 & 0.208 & -0.050 & 0.151 \\
\hline MNHHPAI & $0.168 * * *$ & 0.000 & -0.041 & 0.231 \\
\hline MEDHHINC & -0.028 & 0.660 & 0.045 & 0.429 \\
\hline RNOPOV & $0.120 * * *$ & 0.000 & $0.149 * * *$ & 0.000 \\
\hline RNOWORK & $0.100 * *$ & 0.025 & $0.077 * *$ & 0.012 \\
\hline RTMPWORK & -0.002 & 0.916 & 0.002 & 0.901 \\
\hline \multicolumn{5}{|c|}{ Housing and neighborhood quality } \\
\hline MEDCOREN & 0.053 & 0.380 & $-0.161 * * *$ & 0.000 \\
\hline RRENT & $0.076 * * *$ & 0.007 & $-0.064 * * *$ & 0.004 \\
\hline RENTHINC & -0.028 & 0.616 & $0.091 * *$ & 0.011 \\
\hline RCROWD & $0.069 * * *$ & 0.007 & $0.043 * *$ & 0.029 \\
\hline RVAC & $0.051 * *$ & 0.020 & $0.093 * * *$ & 0.000 \\
\hline RBOARDUP & $0.096 * * *$ & 0.000 & $0.041^{* *}$ & 0.016 \\
\hline$N$ & 1,031 & & 1,030 & \\
\hline$R^{2}$ & 0.704 & & 0.809 & \\
\hline
\end{tabular}

$* p<0.10 . * * p<0.05$. *** $p<0.01$.

the distribution of homeless families' prior addresses is more highly segregated than the poverty distributions. An exception to this pattern is the Bronx, where the rate of shelter admissions is more evenly distributed among the borough's poor neighborhoods, and where the level of risk appears generally high. But, in general, homeless families come primarily from a subset of poor neighborhoods where some additional set factors contribute to their increased risk of public shelter admission.

The regression results support several of the hypotheses concerning the neighborhood characteristics associated with the rate of public-shelter admissions among families. We will focus 
primarily on the New York regression results, which benefited from more observations (census tracts) and thus greater statistical power. We will discuss the Philadelphia results in light of differences between the two cities.

The rate of public-shelter admissions from an area increases with the proportion of African Americans and female-headed households (FHH), particularly those with young children, and to a lesser extent with Hispanic households. These results were predicted, based on previous research, which has shown that homeless families are disproportionately composed of minorities and FHH. Variables for race and FHH with young children continue to be strongly associated with the rate of shelter admission, even controlling for the rate of poverty, welfare receipt, educational attainment, and various housing and labor market variables, which indicates that such households face additional barriers to residential stability not specified in this model.

Areas with high concentrations of $\mathrm{FHH}$ may be at greater risk because of a higher level of risk among individuals in those areas, such as having more limited social network size, higher rates of substance abuse and mental-health problems, and other individual risk factors. However, research comparing housed and homeless Aid to Families with Dependent Children recipients in New York City has shown that there are few such differences in individual risk factors among public assistance recipients and that such individual risk factors affect a relatively small proportion of families entering shelters (Knickman and Weitzman 1989). In addition to these individual-level effects, it is likely that other social and economic barriers, such as restricted residential mobility, limited labor-market access, and various neighborhood effects, have a differential negative impact on FHH with young children and contribute to both their concentration in low-rent areas and their increased risk of public-shelter admission.

A similar set of dynamics may contribute to race and poverty concentrations in a neighborhood, which are among the most significant predictors of shelter admissions for both cities. Again, the increased risk of shelter admission may be partially attributable to a larger number of individual-level risk factors among such groups. However, research has found that race has an additional positive effect on public-shelter use that has not been explained by individual risk factors. For example, AfricanAmerican single adults in Philadelphia have been found to have a significantly longer homelessness duration (controlling for history of mental-health and substance-abuse treatment), and 
African-American homeless families in New York City have been found to have a significantly higher probability of readmission to shelters (controlling for reason for homelessness and type of shelter discharge) (Culhane and Kuhn 1995; Wong, Culhane, and Kuhn forthcoming). Thus, apart from individual risk factors, other social and economic factors are likely to contribute to the differential exposure of predominantly African-American and poor neighborhoods to the risk of public-shelter admission. For example, the high degree of spatial clustering among homeless families' prior addresses found in the descriptive results and the significance of the effects of race and poverty concentration suggest that processes of racial and economic segregation contribute to the increased risk of shelter admission. Such an effect would be consistent with research on the impact of segregation on housing and neighborhood quality. Massey and Denton (1993) have found that increasing racial segregation has interacted with declining income to produce higher poverty concentrations among African Americans over the past two decades, which the authors argue has promoted disinvestment in these communities by concentrating tenants with a decreasing ability to pay market rents in financially distressed buildings. This concentration can produce a "hollowing out" effect, in which units and buildings are more likely to be left vacant or abandoned, a portrait consistent with the neighborhoods identified in this study as being at greatest risk of generating homelessness. Housing market forces and government policies may contribute to increases in spatial stratification by income and race (Schill and Wachter 1995).

The finding that homeless families come from areas with more subfamilies, together with the significance of the crowding variable, provides empirical support for the hypothesis that homelessness is one consequence of "doubling up" in an area. Families doubling up are presumably doing so because of a lack of income for independent household formation. Aside from being at greater risk of a housing emergency because of crowding, people in doubled-up arrangements may also expend sources of social support more quickly in the event of a crisis. For example, people in subfamilies are often already living with parents or other family members prior to public-shelter admission; thus, they have exhausted some of the housing alternatives to which others might have access in the event of a housing emergency.

The interesting exception to the heightened risk associated with crowding is found among recent immigrants. The reversal of the sign relating to the crowding variable in the New York Model II, when the ratio for foreign-born persons is excluded from the regression analysis, suggests that immigrant groups mitigate the 
risk of homelessness by increased crowding. Such groups may have developed adaptations to crowding that prevent or resolve housing emergencies. Alternatively, such persons may be less willing to seek the support of the public-shelter system, even though they may need its services. This area deserves further study, as immigrant communities' accommodations to crowding may help to inform the design of prevention efforts for other communities and families confronting crowding or, alternatively, may reveal a greater need for outreach to immigrant families in need of public shelter. Further research on accommodations to housing distress may also help to explain differences in shelter admissions by race and ethnicity.

The results provide support for hypotheses that family homelessness is related to housing and neighborhood conditions. Homeless families often come from deteriorated and low-rent neighborhoods, as measured by the ratio of boarded-up buildings (among the most important variables in the Philadelphia model) and the median contract rent. Homeless families are also more likely to come from neighborhoods with higher vacancy rates, suggesting that these areas are viewed as relatively undesirable and that the rental housing in these areas is at risk of undermaintenance and abandonment. Affordability matters as well, as indicated by the positive effect of the rent-to-income ratio, confirming the hypothesis that shelter admissions are more likely to occur in areas with a relatively greater rent burden.

The Philadelphia data generally support the findings from New York, though with less statistical significance. Some differences are worth noting, particularly because they might be a function of differences in housing and labor markets, as well as in public policies between the two cities. Among the demographic variables, the effect of the ratio of foreign-born persons immigrating since 1970 is not significant in Philadelphia, nor is the effect of the Hispanic variable. Hispanics constitute a relatively small proportion of the population in Philadelphia (5.6 percent versus 24.4 percent in New York) and are known to be underrepresented among shelter users there. Hispanics and recent immigrants in Philadelphia may be subject to dynamics similar to those of the recent immigrants in New York, whose relatively greater crowding may be an alternate accommodation to housing distress.

Among economic variables, unemployment is significantly related to shelter admission rates in Philadelphia but not in New York. This finding may indicate a relatively greater problem of unemployment in some of that city's neighborhoods. (However, 
the effect of the rate of labor force nonparticipation is significant and positively related to shelter admissions in New York.) The importance of labor market opportunities as a contributing factor in Philadelphia is amplified by the added positive significance of persons temporarily employed.

Finally, among the housing and neighborhood variables, the negative association between the rent-to-income ratio and the rate of shelter admission likely reflects the comparatively lower cost of housing in low-rent areas in Philadelphia (compared with New York), because population loss has resulted in higher vacancy rates. The relatively greater importance of abandonment as a predictor in Philadelphia compared with New York could also be related to Philadelphia's continuing population loss, as well as the higher rate of immigration in New York, where immigrants fill some of the low-cost housing that might otherwise have been left vacant. Differences between cities in the disposition of abandoned and tax-foreclosed properties may also help to explain the more limited effect of abandonment in New York, where local government has assumed more direct responsibility for the management and rehabilitation of tax-foreclosed properties.

Separating tracts by median income in New York also produced some interesting differences from the pooled sample. First, the model performed better for low-income than for higher-income tracts. However, among higher-income tracts, the ratio of African-American persons increases in importance in terms of the standardized coefficient, again raising concerns about the increased risk of homelessness among African-American communities, even those with relatively higher income. The effect of the proportion of rental units also appears more significant in these models, tending to be positive in the case of higher-income areas and significantly negative in low-income areas. This finding may suggest that in low-income areas, homeowner-related housing problems, such as the inability of aging parents or their adult children to maintain the costs of the home, may play a role in increasing the risk of homelessness. In higher-income areas, homelessness is more often related to problems with rental housing and its unaffordability.

From a policy perspective, this research offers two broad insights. First, because the risk of family homelessness is spatially and demographically concentrated, homelessness prevention and outreach efforts would likely benefit from a geographic- and population-targeted strategy. Policies designed to counteract residential segregation, concentrated poverty, and poor housing 
and neighborhood conditions, as well as more narrowly defined homelessness-prevention programs, could target the neighborhoods found to be at greatest risk for generating shelter admissions in this study and the population groups they overrepresent. Second, this study has identified some of the associated factors that could guide the substance of a prevention-oriented policy strategy. For example, improved household income, through expanded rental assistance, improved access to employment income, or increased public assistance benefits, would reduce the poverty and housing unaffordability that this study found to be associated with a higher rate of shelter admission. An incomesupport or housing-subsidy program could also reduce crowding, vacancies, and possibly abandonment, as well as the potential reinforcing effect of these problems on the risk of shelter admissions. Further research is needed to model and test the impact of such policy strategies.

Our study was limited in that the dependent variable represented an aggregation of homeless families' responses to a single query regarding their prior address. Although intake forms for both cities' systems provide some standardization for collecting information, there are no scripts for collecting information from people seeking shelter admission. Some unknown rate of false reporting could also occur because people are responding to questions that partly determine their access to or eligibility for services. Moreover, having found significant and theoretically consistent associations among neighborhood-level variables, the study's results do not diminish the importance of other levels of causal influence, such as intercity effects, emergency-assistance policies, household dynamics, behavioral adaptations, or other individual risk variables. Each of these may influence who among the persons in these areas is at greatest risk of shelter admission and how that risk is distributed geographically. A multilevel or hierarchical analysis would be necessary to examine the differential impact of these factors in a more systematic manner.

Finally, future research should further develop and refine this analytic approach for studying homelessness. This study was limited in treating shelter-admission data and predictive variables cross-sectionally, whereas a more time-sensitive treatment of these variables would be better able to capture the dynamics of change, including population composition, neighborhood quality, and housing conditions. This study was also limited by an aggregation of variables at the level of the census tract, whereas further analyses could examine the block-group-level predictors or even the characteristics of specific properties associated with 
the risk of shelter admission. The analysis could also be further refined by including various spatial measures in the specification of the regression model. Researchers should consider replicating this work in other localities. Such research could be undertaken in areas without computerized shelter-tracking systems by selecting a representative sample of shelter admissions over a given period of time and surveying people about their housing history. The prior-address data could be enhanced by including more detailed questions regarding the housing arrangements of clients. Such an approach would bring greater depth to the understanding of the interaction of neighborhood- and household-level dynamics of housing instability than we could discern with the data available for this study.

\section{Conclusion}

This study has provided empirical support for several hypotheses regarding the influence of housing and income problems in generating homelessness in New York City and Philadelphia, particularly as they disproportionately affect women with young children and African Americans. The rate of public-shelter admission was found to be associated with housing crowding, residence in subfamilies, poverty, restricted access to the labor market, rent burden, and poor neighborhood quality. Future public policies should consider the role of geographic and demographic variations in the risk of homelessness in designing interventions to reduce that risk.

\section{Appendix}

Qualifications of the study population. To assess the degree of bias in the selection of the matched versus unmatched cases, we conducted $t$ tests comparing the groups in each respective city by race and gender of household head (see table A-1). In New York, the matched addresses were significantly more likely to be composed of African-American households $(t=11.445, p<0.0001)$. The matched addresses were also significantly less likely to be composed of Hispanic households $(t=-7.851, p<0.0001)$. However, as shown in table A-1, none of the mean differences between groups was large enough to warrant great concern with the representativeness of the study population (+5.8 percentagepoint difference for African American and -3.9 for Hispanic). Nevertheless, study findings will remain qualified by the fact that the study population for New York City is slightly more likely to represent African-American households and slightly 
Table A-1. Demographics of Matched and Nonmatched Samples in Philadelphia and New York

\begin{tabular}{clcr} 
& & African American & Hispanic \\
\hline Philadelphia & & & \\
Matched sample & Proportion & 0.917 & 0.036 \\
& $N$ & 5,332 & 5,098 \\
Nonmatched sample & Proportion & 0.875 & 0.058 \\
$t$ test for H0 & $N$ & 3,745 & 3,497 \\
& $t$ & 41.897 & 23.181 \\
& $p$ & 0.000 & 0.000 \\
New York & Result & Can reject H0 & Can reject H0 \\
Matched sample & & & \\
Nonmatched sample & Proportion & 0.651 & 0.325 \\
$t$ test for H0 & $N$ & 36,296 & 36,296 \\
& $t$ & 0.593 & 0.364 \\
& $p$ & 12,427 & 12,427 \\
& Result & 11.445 & -7.851 \\
& & 0.000 & 0.000 \\
& & Can reject H0 & Can reject H0
\end{tabular}

Notes: Total number of observations varies due to missing values. H0 = null hypothesis. The means between matched and nonmatched samples are the same.

less likely to represent Hispanics than the overall homeless family population.

In Philadelphia, the address-matched group (the study population) is more likely to include African-American households $(t=41.897, p<0.0001)$ and to underrepresent Hispanic households $(t=23.181, p<0.0001)$. Again, the mean differences are not large (+4.2 percentage points for African American and -2.2 for Hispanic).

We undertook an additional procedure to assess whether a geographically distributed bias operated in the matching and rejection of reported addresses within each city by the geocoding procedures. It is possible that inaccurate base maps or systematically unconventional address reporting resulted in a biased distribution of matched versus rejected in-city addresses. Matched and rejected addresses within each city were thus geocoded by zip code, and the correlation coefficient was computed between the distributions (see table A-2). The matched and rejected addresses are highly similar in distribution in New York City $(r=0.877)$ and nearly identical in Philadelphia $(r=0.972)$, showing that the geographic distribution of the study population in both cities is highly representative of all households reporting in-city addresses, at the zip code level (see table A-2). 
Finally, because these systems were designed for management and not research purposes, both systems are limited in that households with multiple admissions to shelters have their prior address information overwritten at the time of subsequent readmissions. In other words, an address history is not retained for households with multiple shelter admissions. It is conceivable that households readmitted to shelters may have a significantly different locational distribution than households presenting to shelters for the first time. For example, households with multiple admissions may be disproportionately discharged by shelter programs to housing in more or less stable areas relative to the locational origins of households with a single admission. To assess the degree of bias introduced by this possibility, and to assess whether single- and multiple-admission households should be separated for the purposes of the distributional measurements for this study, the correlation between the distribution of prior addresses for households with single versus multiple admissions by zip code for all matched addresses was computed in both cities. Again, however, the distributions are highly similar in New York City $(r=0.992)$ and Philadelphia $(r=0.999)$, suggesting that such a locational difference does not occur at the zip code level and would not warrant further adjustment (see table A-2).

\section{Table A-2. Correlations between the Number of Homeless Families in Each Zip Code in New York and Philadelphia}

\begin{tabular}{lcc} 
Pair of Comparison & New York & Philadelphia \\
\hline Address-matched and nonmatched sample & 0.877 & 0.972 \\
Single and multiple admissions & 0.992 & 0.999
\end{tabular}

Measures of area variations in homelessness rates include the location quotient, unevenness, contiguity, and clustering.

The location quotient (LQ). The LQ cannot have a value less than zero. When the LQ in a locality is greater than 1.00 , the locality has a higher concentration of the subject of interest relative to the other localities of the region combined. Thus, the LQ is used to identify census tracts that contain a higher percentage share of the prior addresses of the homeless, the poor (people below poverty level, as reported in 1990 census), and minority poor than that of Philadelphia or New York as a whole. Because of its unitlessness and absolutivity, the LQ also permits intercity and interborough comparisons of the spatial distribution of the subject of interest. 
Unevenness. The dissimilarity index varies between 0 and 1 , and conceptually it represents the proportion of an object group that would have to change its location to achieve an even distribution. The dissimilarity index is calculated as follows:

Dissimilarity $=\sum_{i}\left[\frac{t_{i}\left|r_{i}-R\right|}{2 T R(1-R)}\right]$,

where $t_{i}$ is population of areal unit $i ; r_{i}$ is homeless proportion of areal unit $i$; and $T$ and $R$ are the total population and the proportion of an object group in the whole, respectively.

Contiguity. The difference between contiguity and unevenness is well illustrated by comparing the case of the "checkerboard problem" (White 1983); highly concentrated areas are located in a scattered fashion like the dark squares on a checkerboard, with a pattern in which the dark and light areas are each clustered together to form two halves on the board (one light, one dark). Both patterns yield the same unevenness index value, although they clearly have different distributional patterns in terms of spatial association. A contiguity index is used to capture this difference in spatial association. In this study, we used an index of spatial autocorrelation to measure the degree of contiguity. If objects that are similar in location also tend to be similar in attributes, the pattern as a whole is said to show positive autocorrelation. Conversely, if objects that are close together in space tend to be more dissimilar in attributes than objects that are farther apart, then negative spatial autocorrelation is displayed (Shen 1994). Moran's I is used to calculate spatial autocorrelation, and its mathematical notation is as follows (Odland 1988):

$I=\frac{n}{\sum_{i} \sum_{j} w_{i j}} \frac{\sum_{i} \sum_{j} w_{i j}\left(p_{i}-\bar{p}\right)\left(p_{j}-\bar{p}\right)}{\sum_{i}\left(p_{i}-\bar{p}\right)^{2}}$,

where $n$ is the number of census tracts; the double summation indicates summation over all pairs of tracts; $p_{i}$ is the ratio of an object group of tract $i$ to the population of tract $i ; \bar{p}$ is the mean of $p_{i}$; and $w_{i j}$ is a proximity weight for the pair of tract $i$ and tract $j$, which is 0 when $i$ equals $j$.

In the geographic literature, the quantity $w_{i j}$ refers to an element in "contiguity matrix" that equals 1 when census tracts $i$ and $j$ are contiguous and 0 otherwise. In this article, adjacent 
tracts of every census tract were identified by using a geographic information system.

Clustering. As a first step in creating a clustering index, we divided census tracts into two groups, based on the LQ: highly concentrated census tracts and census tracts with low concentrations. When two highly concentrated tracts are adjacent to each other, the common boundary lines are deleted and the two polygons of the tracts are merged to form one polygon. If this merging process keeps going, a few polygons that represent highly concentrated areas are obtained. The more unevenly distributed an object group is, the smaller number of tracts categorized as the highly concentrated area will be. The more clustered the highly concentrated tracts are, the more common boundaries are erased, and the smaller the ratio of the sum of the perimeters of the merged polygons to the sum of the perimeters of the original areal units will be. In this concept, the clustering index (CI) can be denoted as follows:

$\mathrm{CI}=1-\frac{\sum_{i^{\prime}} \sum_{j^{\prime}} b_{i^{\prime} j^{\prime}}}{\sum_{i} \sum_{j} b_{i j}}$,

where $b_{i j}$ is the length of common boundary between census tracts $i$ and $j$ before polygon merging; $i^{\prime}$ and $j^{\prime}$ are a pair of census tracts that form the boundaries between the highly concentrated areas and the sparsely concentrated areas.

In the checkerboard example, the sum of the perimeters of highly concentrated polygons persists after the merging process, and CI will be 0 . In the opposite extreme, when the object group is concentrated in a few census tracts adjacent to one another, a single highly concentrated polygon will remain after the polygon merging process, and CI will be close to 1 but will not exceed 1 (see Lee and Culhane [1995] for diagrammatic examples).

Recently, Wong (1993) formulated a new segregation index that uses the length of the common boundary of two areas as an indicator of the degree of social interaction between the residents of the two areas. In a similar context, the total length of common boundaries between the two areal groups (for racial segregation, minority area, and majority area) may be interpreted as the total possibility of social interaction between the two groups. The total length of the common boundaries between the areas belonging to the same areal group may be interpreted as the total possibility of social interaction within a group. Therefore, the clustering index measures how small total social 
interaction between the two groups is compared to the sum of total interaction between the two groups and total interaction within groups.

\section{Authors}

Dennis P. Culhane is Associate Professor in the School of Social Work and Research Associate Professor in the Center for Mental Health Policy and Services Research at the University of Pennsylvania. Chang-Moo Lee is Senior Fellow at The Wharton School Real Estate Center of the University of Pennsylvania. Susan M. Wachter is Professor of Real Estate and Finance at The Wharton School of the University of Pennsylvania.

This research was supported by a grant from the Edna McConnell Clark Foundation, Program for New York Neighborhoods. The authors gratefully acknowledge the assistance of Mon Louie of the City of New York Human Resources Administration, Heide Lange-Joe of the City of New York Department of Homeless Services, and Joseph Henry and June Averyt of the University of Pennsylvania for their assistance with this project.

\section{References}

Applebaum, Richard, M. Dolny, Peter Dreier, and John Gilberbloom. 1991. Scapegoating Rent Control: Masking the Causes of Homelessness. Journal of the American Planning Association 57:153-64.

Applebaum, Richard, M. Dolny, Peter Dreier, and John Gilberbloom. 1992. Sham Rent Control Research: A Further Reply. Journal of the American Planning Association 58:220-24.

Bendavid-Val, Avrom. 1983. Regional and Local Economic Analysis for Practitioners. New York: Praeger.

Blau, Joel. 1992. The Visible Poor: Homelessness in the United States. New York: Oxford University Press.

Burt, Martha. 1992. Over the Edge: The Growth of Homelessness in the 1980s. New York and Washington: Russell Sage Foundation and The Urban Institute Press.

Burt, Martha. 1994. Comment. Housing Policy Debate 5(2):141-52.

Culhane, Dennis P. 1990. The Social Selection Processes of Homelessness. In On Becoming Homeless: The Structural and Experiential Dynamics of Residential Instability, 135-47. Unpublished doctoral dissertation. Boston College.

Culhane, Dennis P. 1992. The Quandaries of Shelter Reform: An Appraisal of Efforts to "Manage" Homelessness. Social Service Review 66(3):428-40.

Culhane, Dennis P., Edmund F. Dejowski, Julie Ibanez, Elizabeth Needham, and Irene Macchia. 1994. Public Shelter Admission Rates in Philadelphia and New York City: The Implications of Turnover for Sheltered Population Counts. Housing Policy Debate 5(2):107-40. 
Culhane, Dennis P., and Randall Kuhn. 1995. Patterns and Determinants of Shelter Utilization Among Single Adults in New York City and Philadelphia: A Longitudinal Analysis of Homelessness. Paper presented at the Annual Meeting of the Eastern Sociological Association, March 31, Philadelphia, PA.

Elliot, Marta, and Lauren J. Krivo. 1991. Structural Determinants of Homelessness in the U.S. Social Problems 38(1):113-31.

Fournier, Louise, Malijai Caulet, Gilles Cote, Jean Toupin, Maurice Ohayon, Micheline Ostoj, and Isabelle Laurin. 1994. Longitudinal Study of the New Homeless: Preliminary Results. Paper presented at the Annual Meeting of the American Public Health Association, November 1, Washington, DC.

Hopper, Kim. 1990. The New Urban Niche of Homelessness: New York City in the Late 1980s. Bulletin of the New York Academy of Medicine 66(5):435-50.

Hopper, Kim. 1995. Definitional Quandaries and Other Hazards in Counting the Homeless: An Invited Commentary. American Journal of Orthopsychiatry 65(3):340-46.

Hopper, Kim, and Jill Hamberg. 1986. The Making of America's Homeless: From Skid Row to New Poor, 1945-1986. In Critical Perspectives on Housing, eds. Rachel Bratt, Chester Hartman, and Ann Meyerson, 12-40. Philadelphia: Temple University Press.

Interagency Council for the Homeless. 1994. Priority Home: The Federal Plan to Break the Cycle of Homelessness. Washington: U.S. Department of Housing and Urban Development.

Jahiel, Rene. 1992. Toward the Prevention of Homelessness. In Homelessness: A Prevention Oriented Approach, ed. Rene Jahiel, 315-36. Baltimore: The Johns Hopkins University Press.

James, David R., and Karl E. Taeuber. 1985. Measures of Segregation. In Sociological Methodology 1985, ed. Nancy Tuman, 1-32. San Francisco: Jossey-Bass.

Kearns, Robin A., and Christopher J. Smith. 1994. Housing, Homelessness and Mental Health: Mapping an Agenda for Geographical Inquiry. Professional Geographer 46(4):418-24.

Knickman, James, and Beth Weitzman. 1989. Forecasting Models to Target Families at High Risk of Homelessness. New York: New York University Health Research Program.

Koegel, Paul, and M. Audrey Burnam. 1994. The Course of Homelessness Among Homeless Adults in Los Angeles. Paper presented at the Annual Meeting of the American Public Health Association, November 1, Washington, DC.

Kondratas, Anna. 1994. Comment. Housing Policy Debate 5(2):153-62.

Lee, Chang-Moo, and Dennis P. Culhane. 1995. The Spatial Distribution of Homelessness Occurrence and the Efficacy of Shelter Programs in Philadelphia. Wharton Real Estate Center Working Paper Series No. 213. University of Pennsylvania. 
Lindblom, Eric N. 1991. Toward a Comprehensive Homelessness-Prevention Strategy. Housing Policy Debate 2(3):631-47.

Link, Bruce G., Ezra Susser, Anne Stueve, Jo Phelan, Robert E. Moore, and Elmer Struening. 1994. Lifetime and Five-Year Prevalence of Homelessness in the United States. American Journal of Public Health 84:1907-12.

Massey, Douglas S., and Nancy A. Denton. 1988. The Dimensions of Residential Segregation. Social Forces 67(2):281-315.

Massey, Douglas S., and Nancy A. Denton. 1993. American Apartheid: Segregation and the Making of the American Underclass. Cambridge, MA: Harvard University Press.

Odland, John. 1988. Spatial Autocorrelation. New York: Sage Publications.

Piliavin, Irving, Michael Sosin, Alex H. Westerfelt, and Ross L. Matsueda. 1993. The Duration of Homeless Careers: An Exploratory Study. Social Service Review 67:576-98.

Quigley, J. 1991. Does Rent Control Cause Homelessness? Taking the Claim Seriously. Journal of Policy Analysis and Management 9:89-93.

Ringheim, Karen. 1990. At Risk of Homelessness: The Roles of Income and Rent. New York: Praeger.

Robertson, Marjorie J., Cheryl Zlotnick, and Alex Westerfelt. 1994. The Course of Homelessness Among Adults and Families in Alameda County. Paper presented at the Annual Meeting of the American Public Health Association, November 1, Washington, DC.

Rossi, Peter. 1989. Down and Out in America. Chicago: University of Chicago Press.

Rossi, Peter. 1994. Comment on Dennis P. Culhane et al.'s "Public Shelter Admission Rates in Philadelphia and New York City: The Implications of Turnover for Sheltered Population Counts." Housing Policy Debate 5(2): 163-76.

Schill, Michael H., and Susan M. Wachter. 1995. Housing Market Constraints and Spatial Stratification by Income and Race. Housing Policy Debate 6(1): 141-67.

Shen, Qing. 1994. An Application of GIS to the Measurement of Spatial Autocorrelation. Computer, Environment, and Urban Systems 18(3):167-91.

Stegman, Michael A. 1993. Housing and Vacancy Report: New York City, 1991. New York: Department of Housing Preservation and Development.

Tucker, W. 1987. Where Do the Homeless Come From? National Review, September, pp. 32-45.

U.S. Department of Commerce. 1993. TIGER/Line 1992. Washington, DC: Bureau of Data User Services Division.

U.S. Department of Health and Human Services. 1991. Homelessness Prevention Programs. Washington, DC: Office of the Inspector General. 
U.S. Department of Housing and Urban Development. 1984. A Report to the Secretary on the Homeless and Emergency Shelters. Washington, DC: Office of Policy Development and Research.

Wallace, Roderick. 1989. "Homelessness," Contagious Destruction of Housing and Municipal Service Cuts in New York City: 1. Demographics of a Housing Deficit. Environment and Planning A 21:1585-1603.

Wallace, Roderick. 1990. "Homelessness," Contagious Destruction of Housing and Municipal Service Cuts in New York City: 2. Dynamics of a Housing Famine. Environment and Planning A 22:5-15.

White, Michael J. 1983. The Measurement of Spatial Segregation. American Journal of Sociology 88(5):1008-18.

Wolch, Jennifer, and Michael Dear. 1993. Malign Neglect. San Francisco: Jossey-Bass.

Wong, David W. S. 1993. Spatial Indices of Segregation. Urban Studies 30(3):559-72.

Wong, Irene, Dennis P. Culhane, and Randall Kuhn. Forthcoming. Predictors of Shelter Exit and Return among Homeless Families in New York City. Available from authors, University of Pennsylvania.

Wright, James D., and Joel A. Devine. 1995. Housing Dynamics of the Homeless: Implications for a Count. American Journal of Orthopsychiatry 65(3): 320-29. 
